\title{
28 Resarch Soure \\ Predicting the potential distribution of the parasitic Cuscuta chinensis under global warming
}

\section{Zichun Ren}

Shanxi Normal University

Lyuben Zagorchev

Sofia University

Junxia Ma

Taizhou University

\section{Ming Yan}

Shanxi Normal University

Junmin Li ( $D$ lijmtzc@126.com)

Taizhou University https://orcid.org/0000-0001-8244-0461

\section{Research article}

Keywords: Cuscuta chinensis, Maxent model, Bioclimatic variables, Species distribution, Climatic warming

Posted Date: December 19th, 2019

DOI: https://doi.org/10.21203/rs.2.19302/v1

License: (c) (i) This work is licensed under a Creative Commons Attribution 4.0 International License. Read Full License

Version of Record: A version of this preprint was published at BMC Ecology on May 9th, 2020. See the published version at https://doi.org/10.1186/s12898-020-00295-6. 


\section{Abstract}

Background: The climate is the dominant factor that affects the distribution of plants. Cusucta chinensis is a stem holoparasitic plant without leaves or roots, which develops a haustorium and sucks nutrients from host plants. The potential distribution of the parasitic plant $C$. chinensis has not been predicted to date. This study used Maxent modeling to predict the potential distribution of $C$. chinensis, based on the following six main bioclimatic variables: annual mean temperature, isothermality, temperature seasonality, precipitation seasonality, precipitation of the warmest quarter, and precipitation of the coldest quarter.

Results: The optimal annual average temperature and isothermality of $C$. chinensis ranged from 4 to $37^{\circ} \mathrm{C}$ and less than 45 , respectively, while the optimal temperature seasonality and precipitation seasonality ranged from 4000 to 25000 and from 50 to 130, respectively. The optimal precipitation of the warmest season ranged from 300 to $1000 \mathrm{~mm}$ and from 2500 to $3500 \mathrm{~mm}$, while that of the coldest season was less than $20000 \mathrm{~mm}$. In Asia, C. chinensis is mainly distributed at latitudes ranging from $20^{\circ}$ to $50^{\circ}$. During three specific historical periods (last glacial maximum, mid-Holocene, and 1960-1990) the habitats suitable for $C$. chinensis were concentrated in the central, northern, southern, and eastern parts of China. From the last glacial maximum to the mid-Holocene, the total area with suitability of $0.5-1$ increased by 0.0875 million $\mathrm{km} 2$; however, from the mid-Holocene to $1960-1990$, the total area with suitability of $0.5-1$ decreased by 0.0759 million $\mathrm{km} 2$. The simulation results of habitat suitability in the two representative concentration pathways (RCP) 2.6 (i.e., the low greenhouse gas emissions pathway) and 8.5 (i.e., the high greenhouse gas emissions pathway) indicate that the habitat suitability of $C$. chinensis decreased in response to the warming climate. Compared with RCP2.6, areas with averaged suitability and highsuitability for survival (RCP8.5) decreased by 0.18 million $\mathrm{km} 2$.

Conclusion: Suitable habitats of $C$. chinensis are situated in central, northern, southern, and eastern China. The habitat suitability of $C$. chinensis decreased in response to the warming climate. These results provide a reference for the management of $C$. chinensis.

\section{Background}

The climate is the dominant factor to affect plant distribution [1, 2, 3, 4]. Under the context of global climate change, increasing attention has been focused on the prediction of the distribution of plants to better apprehend future trends [4]. In addition to species distributed in unique habitats, such as arid regions [5], highlands [4], and capes [6], most studies focused on specific species, such as dominant forest species [7, 8], invasive species $[9,10]$, or rare species [3] to enable better management of species. However, to date, only few studies focused on parasitic plants $[11,12]$.

By definition, parasitic plants obtain all or part of their energy from autotrophic plants (producers) via haustaria, and are ubiquitous species in all ecosystems [13]. Most of the parasitic plants are harmful to agriculture since they absorb a notable share of the host plants' nutrients, which ultimately decreases or even inhibits host growth and can lead to the death of the host due to insufficient nutrition [14]. However, many parasitic plants are also used as medicine, such as Cuscuta chinensis [15], Cistanche deserticola [16], and Viscum coloratum [17]. Predicting the potential global distribution of such parasitic plants not only informs 
management procedures that enable a reduction of the harm parasitic species impose on agriculture, it is also useful for the development of medical applications. Until now, the distribution of $\mathrm{C}$. chinensis has not been predicted.

Ecological niche models (ENMs) are standard in ecological modelling [18]. ENMs are a classical method that utilizes occurrence data in conjunction with environmental data to build a correlative model of the specific environmental conditions that meet a species' ecological requirements and thus predict the relative habitat suitability [19]. ENMs use layers of environmental information and species, as well as pseudo-absence or absence points to develop probabilistic maps of suitable distribution [20]. ENMs are generally used for four main objectives: (1) to estimate the relative suitability of the habitat that is currently occupied by the species to be assessed, (2) to estimate the relative habitat suitability in areas where the assessed species are currently not known to be present, (3) to estimate potential changes in the habitat suitability due to scenarios of environmental change, and (4) to estimate the environmental niche of a species [21]. Among the available tools for ENMs, the maximum entropy (Maxent) approach is one of the most widely used for the prediction of species distributions [20,22]. Moreover, Maxent is effective for the prediction of narrow species distributions $[2,3,23,24,25,26,27]$.

Cuscuta spp. belong to the family of Convolvulaceae and are annual holoparasitic herbs. Cuscuta spp. grow in a wide variety of climates and ecosystems on all continents except Antarctica [28]. Cuscuta spp. severely damage crop plants and are considered as the third-most detrimental group of parasitic pants worldwide following Striga and Orobance [28]. C. chinensis is a typical native holoparasitic plant belonged to Cuscuta genus in China, which is also known as the Chinese Dodder [29], or Tu-Si-Zi in Chinese [30]. This study used the Maxent method to predict the potential distribution of $\mathrm{C}$. chinensis based on world-wide occurrence data of $\mathrm{C}$. chinensis. This study aimed to identify: 1 ) the climatic factors that affect the suitability of $\mathrm{C}$. chinensis habitat, 2) how the distribution of $\mathrm{C}$. chinensis changed during three historical periods (last glacial maximum, mid-Holocene, and 1960-1990), and 3) how the C. chinensis distribution changed in response to global warming. The results provide a basic understanding of the trends of parasitic Cuscuta spp. plants within the plant community and improve the management and control of this species.

\section{Methods}

\section{Study species}

C. chinensis grows near the seaside, its stems are thin, twining, filiform, glabrous, yellowish or pale yellowish, and have a diameter of $\sim 1 \mathrm{~mm}$. The plant has neither roots nor leaves, or leaves that are reduced to minute scales [29]. It often parasitizes on Fabaceae, Asteraceae, or Zygophyllaceae. C. chinensis is distributed throughout Asia and Australia $[29,30]$. Its aerial parts are harvested in autumn, when the fruits are ripe, and are dried naturally via sunlight. Dried parts are thrashed for seeds [28, 29]. C. chinensis seeds are often used as herbal medicine, and have the functions to improve the metabolism of the liver and kidney, are used as a diuretic, and can improve eyesight [15, 31, 32].

\section{Data sources}


Occurrence records (818) of $\mathrm{C}$. chinensis were collected from the national specimen information infrastructure (http://www.nsii.org.cn/), the Chinese virtual herbarium (http://www.cvh.org.cn/), and the plant photo bank of China (http://ppbc.iplant.cn/). Moreover, 175 occurrence records were collected from the global biodiversity information facility (GBIF; http://www.gbif.org; accessed on June 26, 2018). Four occurrence records were collected from scientific publications. 550 same-latitude and longitude-repeated records as well as four invalid records (occurrence points of the bioclimatic variable raster layer with a value of -9999) were deleted. Finally, 443 valid records were used for the analysis herein.

Bioclimatic factors exert important biological significance for the determination of the environmental niche of species [2]. Since the GBIF database has a spatially-biased dataset due to variable sampling efforts, data storage, and mobilization below 30 arc sec resolution [33], only data of 19 bioclimatic factors with 2.5 (4.3 $\times$ $\left.4.3 \mathrm{~km}^{2}\right), 5\left(10 \times 10 \mathrm{~km}^{2}\right)$, and 10 arc $\min \left(16 \times 16 \mathrm{~km}^{2}\right)$ resolution were downloaded (http://www.worldclim.org). The climate data for the three periods (last glacial maximum, Mid-Holocene, and 1960-1990) also originate from http://www.worldclim.org.

The paleoclimatic prediction was conducted with the CCSM4 climate model. The representative concentration pathways (RCPs) are four greenhouse gas concentration (rather than emission) trajectories that have been adopted by the Intergovernmental Panel on Climate Change (IPCC) [4]. Four RCPs (RCP2.6, RCP4.5, RCP6.0, and RCP8.5) represent net radiative forcing of $2.6,4.5,6.0$, and $8.5 \mathrm{~W} / \mathrm{m}^{2}$ at the end of the year $2100[34,35]$. The most representative RCP2.6 and RCP8.5 with the lowest and highest net radiation intensity at the end of 2100 , respectively, were used for this study. The RCP2.6 scenario results in $490 \mathrm{ppm}$ $\mathrm{CO}_{2}$ equivalent and a global average temperature increase of $1.5^{\circ} \mathrm{C}$, while the RCP8.5 scenario results in $1370 \mathrm{ppm} \mathrm{CO}$ equivalent and a global average temperature increase of $5.0^{\circ} \mathrm{C}[36,37]$. C. chinensis habitat suitability distributions were modeled for each of these two scenarios. In both cases, the habitat suitability distribution of C. chinensis was simulated separately. Climate projections for the years 2061 through to 2080 were used as climate data and were obtained from global climate models (GCMs) for RCP2.6 and RCP8.5, which are available at http://www.worldclim.org. Geographical base map data were downloaded from the national basic geographic information system (http://www.diva-gis.org/).

\section{Bioclimatic variable screening}

To avoid the influence of highly relevant environmental data on the prediction results, both Pearson correlation coefficient and principal component analysis (PCA) of 19 bioclimatic variables were tested using the SPSS 19.0 software (SPSS Inc. Chicago, IL USA). One variable of each set of highly cross-correlated variables $(r>0.8)$ was selected for further analysis [2]. Various environmental factors were considered and the most relevant factors for prediction and evaluation were selected [38, 39]. Subsequently, the Maxent model was used to calculate the contribution rate of the 19 selected environmental factors. According to the 19 bioclimatic variables presented in Table 1, 10\% of the distributed information points were randomly selected as test sets, and the remaining $90 \%$ of the samples were used as training set for model verification. The model settings were repeated 10 times. Six bioclimatic variables were screened to explore the response 
of C. chinensis to climate change. Then, the Jackknife test was used to test the contribution rate of bioclimatically dominant factors $(>0.4)$.

Table 1

Bioclimatic variables used in the model and the relative contributions of 19 bioclimatic variables to the Maxent model for $\mathrm{C}$. chinensis

\begin{tabular}{|lll|}
\hline Variables & Description & Percent contribution \\
\hline BIO1 & Annual Mean Temperature & 8.6 \\
\hline BIO2 & Mean Diurnal Range (Mean of monthly (max temp - min temp)) & 1.8 \\
\hline BIO3 & Isothermality (BIO2/BIO7) (* 100) & 6.4 \\
\hline BIO4 & Temperature Seasonality (standard deviation *100) & 13.1 \\
\hline BIO5 & Max Temperature of Warmest Month & 1.4 \\
\hline BIO6 & Min Temperature of Coldest Month & 1.8 \\
\hline BIO7 & Temperature Annual Range (BIO5-BIO6) & 1.3 \\
\hline BI08 & Mean Temperature of Wettest Quarter & 1.1 \\
\hline BIO9 & Mean Temperature of Driest Quarter & 3.9 \\
\hline BI010 & Mean Temperature of Warmest Quarter & 2 \\
\hline BI011 & Mean Temperature of Coldest Quarter & 3.6 \\
\hline BI012 & Annual Precipitation & 1.6 \\
\hline BI013 & Precipitation of Wettest Month & 8 \\
\hline BI014 & Precipitation of Driest Month & 1.2 \\
\hline BI015 & Precipitation Seasonality (Coefficient of Variation) & 13.4 \\
\hline BI016 & Precipitation of Wettest Quarter & 1.3 \\
\hline BI017 & Precipitation of Driest Quarter & 1.2 \\
\hline BI018 & Precipitation of Warmest Quarter & 24.1 \\
\hline BI019 & Precipitation of Coldest Quarter & 4.2 \\
\hline
\end{tabular}

\section{Maxent modelling}

The principle of Maxent is a criterion for the selection of statistical characteristics of random variables that best meet the objective conditions. This is also known as the principle of maximum information. The probability distribution of random quantities is difficult to measure. Generally, only mean values (such as the mathematical expectation and variance) or values under specific defined conditions (such as peak values 
and the number of values) can be measured. The distribution of these values can be measured in a variety of ways, and thus, an infinite number of distributions can be investigated. Typically, one of these distributions has the highest entropy. Selecting this distribution with the highest entropy (Maxent) as distribution of the random variable is an effective processing method and criterion. This Maxent approach establishes a model with Maxent in accordance with known data [23,40]. Maxent uses all grid elements in a certain study area, thus using the largest possible distribution space. It also uses the grid unit of the known species distribution point as sample point, and obtains the constraining conditions according to the environmental variables of the sample point unit to identify the Maxent under this constraint condition. This approach yields the possible distribution $[23,40]$ with simple operation, fast calculation speed, and good prediction result [41, 42, 43]. Based on the Maxent theory, the Java-based software package Maxent was developed by Phillips et al. [44] and can be used to simulate habitat suitability. The present study used Maxent modelling to predict the potential distribution of $\mathrm{C}$. chinensis. The maximum information entropy model Maxent software (version 3.4.1) was obtained from the official website (http://biodiversityinformatics.amnh.org/opensource/maxent/) [45].

\section{Model evaluation index}

The area under curve (AUC) value and the true statistic test (TSS) index respond differently to distribution point occurrence rates and thresholds; therefore, their combination can better assess the performance of the model $[46,47]$. Both AUC and TSS were used to evaluate the performance of the model [46]. The AUC value was directly obtained after running the Maxent software [46]. The receiver operating characteristic (ROC) curve is based on the accuracy of the threshold-independent evaluation model, i.e., each value of the prediction result is used as possible judgment threshold. The corresponding sensitivity and specificity were calculated via the ROC curve. The specificity (1-specificity; i.e., the probability for being predicted to be positive without the species distribution) is shown on the abscissa, and the sensitivity (1-omission rate; i.e., the probability that the species is actually distributed and predicted to be positive) is shown on the ordinate. The AUC value was calculated as the area enclosed by the curve and the abscissa and was used to assess the performance of models that are not affected by the choice of the threshold [48]. In general, the AUC ranges between 0.5 and 1. A larger AUC value indicates better model performance [2]. Model performance is categorized as failing (0.5-0.6), poor (0.6-0.7), fair (0.7-0.8), good (0.8-0.9), or excellent (0.9-1) according to the AUC [47].

The TSS provides a threshold-dependent measure of accuracy, which is often applied for presence-absence predictions [46]. Models that generate such presence-absence predictions (hereafter referred to as presenceabsence models) are usually evaluated by comparing the predictions with a set of validation sites.

Furthermore, these models can be evaluated by constructing a confusion matrix that records the number of true positive (a), false positive (b), false negative (c), and true negative (d) cases predicted by the model [46]. Models that generate non-dichotomous scores on an ordinal scale (hereafter referred to as ordinal score models) are often evaluated by applying a specific threshold to transform scores into a dichotomous set of presence-absence predictions, which can be used to construct a corresponding confusion matrix. Sensitivity and specificity are two alternative measures that are often derived from the confusion matrix. Sensitivity is 
the proportion of observed presences that are predicted as such, and therefore quantifies omission errors. The calculation formula is:

$$
\text { Sensitivity }=\frac{a}{a+c}
$$

where $\mathrm{a}$ is the number of cells for which the presence was correctly predicted by the model; $\mathrm{c}$ is the number of cells for which the species was found but the model predicted absence. Specificity is the proportion of observed absences that are predicted as such, and therefore quantifies commission errors. The calculation formula is:

Specificity $=\frac{d}{b+d}$

where $b$ is the number of cells for which the species was no found but the model predicted presence, $d$ is the number of cells for which absence was correctly predicted by the model. The TSS index was calculated as: TSS = Sensitivity + Specificity -1 . Model performance is either categorized as failing $(<0.4)$, poor $(0.4-0.55)$, fair (0.55-0.7), good (0.7-0.85), or excellent (0.85-1) according to the TSS [46].

\section{Model setting}

This study randomly established 10000 validation sites, and used the actual point of existence to run the model. To obtain the best model, the Maxent model was set as follows: (1) the regularization multiplier (beta) was set to $1,2,5,10,15$, and $20[19,49]$. (2) A 10 cross-validation approach was used as replicated run type [22]. (3) A complementary log-log (cloglog) transformation was used to produce an estimate of the habitat suitability of weeds [45]. (4) The resolutions of environmental variables were set to 2.5, 5.0, and 10.0 arc min. The Maxent model was run 10 times repeatedly. Each run randomly selected $90 \%$ of the distribution information points as training set, while the remaining $10 \%$ of the samples were used for the test. The threshold rule selected equal training sensitivity and specificity. The output format of Maxent was selected automatically depending on the particular sample size of the occurrence records according to a method developed by Phillips and Dudik [40]. The auto feature setting was selected and the regularization multiplier (beta) was 1. In addition, the environmental variable was set to $2.5 \mathrm{~min}$. Under this Maxent output format, AUC and TSS values were highest $(A U C=0.952$, TSS $=0.894)$, indicating very good model performance.

\section{Predicting the suitable area of $\mathrm{C}$. chinensis under global climate change}

ArcGIS 10.2 software (ESRI Inc., Redlands, CA, USA) was used to superimpose and map the results of the Maxent model calculations. Based on the main ecological factors, a global map of ecologically appropriate 
zones for C. chinensis was drawn. Artificial grading was used to classify different grades based on their ecological similarity. According to the statistical principle, the expression of probability "existence" and the empirical method divided the suitable area into four levels $[50,51,52]$. These levels are: $<25 \%$, which is representative for non-suitable survival areas, and indicates that the suitability for the survival of species in these areas is below $25 \%$. A level of $25-50 \%$ is representative for low-suitable survival areas, a level of $50-$ $75 \%$ is representative for survival areas with average suitability, and a level of $>75 \%$ is representative for high-suitable for survival area. These three levels indicate that species have a higher probability of survival in these areas $[50,51,52]$. The optimal ranges of the climatic variables were defined as those ranges where species inhabited survival areas with average and high suitability, i.e. $>50 \%[50,51,52]$. The range of appropriate eco-factor values was derived from the response curves of the Maxent model results.

\section{Results}

\section{Model performance and contribution of variables}

Ecological modeling yielded an average AUC value of 0.951 (Fig. 1), while the TSS index was 0.887 , classifying the model as very satisfactory. The six bioclimatic variables of annual mean temperature (Bio1), isothermality (Bio3), temperature seasonality (Bio4), precipitation seasonality (Bio15), precipitation of warmest quarter (Bio18), and precipitation of coldest quarter (Bio19) were selected to establish the model (Table 2). Fig. S1 shows the results of the Jackknife test of the variable contribution by Maxent. When used independently, Bio1, Bio3, Bio15, and Bio18 provided very high gains $(>0.40)$, indicating that these three variables contained more useful information than the other variables. Bio4 and Bio19 achieved very low yields when used alone, and did not contain much information. Therefore, Bio1, Bio3, Bio15, and Bio18 were identified as important climatic factors that influence the suitable habitat of $\mathrm{C}$. chinensis.

Table 2

Environmental variables used for modeling the habitat suitability distribution of $\mathrm{C}$. chinensis in this study

\begin{tabular}{|c|c|c|c|c|}
\hline $\begin{array}{l}\text { Data } \\
\text { source }\end{array}$ & Category & Variables & Abbreviation & Units \\
\hline \multirow{6}{*}{$\begin{array}{l}\text { C. } \\
\text { Chinensis } \\
\text { Worldclime }\end{array}$} & Bioclimatic & Annual Mean Temperature & Bio1 & ${ }^{\circ} \mathrm{C}$ \\
\hline & & Isothermality (BIO2/BIO7) $(* 100)$ & Bio3 & Dimensionless \\
\hline & & $\begin{array}{l}\text { Temperature Seasonality (standard } \\
\text { deviation *100) }\end{array}$ & Bio4 & Dimensionless \\
\hline & & $\begin{array}{l}\text { Precipitation Seasonality (Coefficient of } \\
\text { Variation) }\end{array}$ & Bio15 & Dimensionless \\
\hline & & Precipitation of Warmest Quarter & Bio18 & $\mathrm{mm}$ \\
\hline & & Precipitation of Coldest Quarter & Bio19 & $\mathrm{mm}$ \\
\hline
\end{tabular}


Table 3

The area of Cuscuta chinensis's four habitat suitability distribution during three historical periods. PCT indicates the percentage of the area in the current historical periods relative to the area in the last historical periods. TAPCT indicates the percentage of the area in the current historical periods of area increase ("+") and decrease ("-") (The percentage increase and decrease in the area of the column compared to the area of the previous column in the historical period.) and the percentage (PCT) of the global's total area.

\begin{tabular}{|c|c|c|c|c|c|c|c|c|c|}
\hline \multirow{3}{*}{$\begin{array}{l}\text { Habitat } \\
\text { suitability }\end{array}$} & \multicolumn{9}{|c|}{ Historical periods } \\
\hline & \multicolumn{3}{|c|}{ Last glacial maximum } & \multicolumn{3}{|c|}{ Mid-Holocene } & \multicolumn{3}{|c|}{$1960-1990$} \\
\hline & $\begin{array}{l}\text { Area } \\
(\text { million } \\
\left.\mathrm{km}^{2}\right)\end{array}$ & $\begin{array}{l}\text { PCT } \\
(\%)\end{array}$ & $\begin{array}{l}\text { TAPCT } \\
(\%)\end{array}$ & $\begin{array}{l}\text { Area } \\
\text { (million } \\
\mathrm{km}^{2} \text { ) }\end{array}$ & $\begin{array}{l}\text { PCT } \\
(\%)\end{array}$ & $\begin{array}{l}\text { TAPCT } \\
(\%)\end{array}$ & $\begin{array}{l}\text { Area } \\
\text { (million } \\
\mathrm{km}^{2} \text { ) }\end{array}$ & $\begin{array}{l}\text { PCT } \\
(\%)\end{array}$ & $\begin{array}{l}\text { TAPCT } \\
(\%)\end{array}$ \\
\hline $0-0.25$ & 140.0203 & 1 & 94.04 & 140.6176 & +0.43 & 94.44 & 140.7554 & $\stackrel{+}{0.01}$ & 94.53 \\
\hline $0.25-0.5$ & 4.0135 & 1 & 2.70 & 3.3286 & -17.06 & 2.24 & 3.2669 & -1.86 & 2.19 \\
\hline $0.5-0.75$ & 2.5989 & 1 & 1.75 & 2.1175 & -18.52 & 1.42 & 2.1213 & $\begin{array}{l}+ \\
0.18\end{array}$ & 1.42 \\
\hline $0.75-1$ & 2.2673 & 1 & 1.52 & 2.8362 & $\stackrel{+}{25.09}$ & 1.90 & 2.7565 & -2.81 & 1.85 \\
\hline
\end{tabular}

Table 4

The area of Cuscuta chinensis's four habitat suitability distribution for two global warming scenarios. PCT indicates the percentage of the area in the current historical periods relative to the area in the last historical periods.

\begin{tabular}{|lllll|}
\hline Habitat suitability & \multicolumn{3}{l}{ Global warming scenarios } & \\
\cline { 2 - 5 } & PCR2.6 & & PCR8.5 & \\
\hline & Area (million $\left.\mathrm{km}^{2}\right)$ & PCT (\%) & Area (million $\left.\mathrm{km}^{2}\right)$ & PCT (\%) \\
\hline $0-0.25$ & 140.8488 & 94.59 & 141.1786 & 94.81 \\
\hline $0.25-0.5$ & 2.9526 & 1.98 & 2.8043 & 1.88 \\
\hline $0.5-0.75$ & 2.2519 & 1.51 & 2.0183 & 1.36 \\
\hline $0.75-1$ & 2.8467 & 1.91 & 2.8988 & 1.95 \\
\hline
\end{tabular}

\section{Response of variables to suitability}

The response curves of $\mathrm{C}$. chinensis to the six assessed bioclimatic variables are shown in Fig. S2. As shown in Fig. S2a, when Bio1 is below $5{ }^{\circ} \mathrm{C}$, the probability that C. chinensis exists is extremely low (below 0.5 , 
indicating low probability). With increasing temperature, the probability for $\mathrm{C}$. chinensis to exist gradually increased, and reached the maximum at $22^{\circ} \mathrm{C}$ with a probability of existence as high as 0.7 . When Bio1 ranges from $4{ }^{\circ} \mathrm{C}$ to $37^{\circ} \mathrm{C}$, the survival rate of $\mathrm{C}$. chinensis was high $(\sim 0.5)$. Therefore, the optimum annual mean temperature of $\mathrm{C}$. chinensis ranges from $4{ }^{\circ} \mathrm{C}$ to $37^{\circ} \mathrm{C}$.

As shown in Fig. S2b, when Bio3 ranged from 0 to 45, the survival probability of C. chinensis exceeded 0.5, indicating a benefit for the survival of $\mathrm{C}$. chinensis. Therefore, the optimum isothermality of $\mathrm{C}$. chinensis should remain below 45 .

As shown in Fig. S2c, when the temperature seasonality of Bio4 was $\sim 500$ or less, the existence probability of C. chinensis was extremely low. Furthermore, from 4000 to 25000 , the survival probability of C. chinensis first increased and then decreased, and the survival probability of $\mathrm{C}$. chinensis decreased to above 0.5 . Therefore, the optimal temperature seasonality of C. chinensis is $4000-15000$.

As shown in Fig. S2d, when Bio15 exceeds 25, the survival probability of C. chinensis rapidly increased and reached a peaked at around $80(\sim 0.72)$. From 50 to 130 , the survival probability of $C$. chinensis exceeded 0.5. Therefore, the optimal precipitation seasonality ranges from 50 to 130.

As shown in Fig. S2e, with increasing Bio18, the survival probability of C. chinensis gradually increased and peaked at around $500 \mathrm{~mm}$. Beyond $500 \mathrm{~mm}$, the survival probability of $\mathrm{C}$. chinensis deceased and reached a minimum at around $1400 \mathrm{~mm}$. Furthermore, the optimal precipitation of the warmest quarter ranges from $300 \mathrm{~mm}$ to $1000 \mathrm{~mm}$, and from $2500 \mathrm{~mm}$ to $3500 \mathrm{~mm}$ with the survival probability of C. chinensis exceeding 0.5 .

As shown in Fig. S2f, when Bio19 ranged from 0 to $2000 \mathrm{~mm}$, the existence probability of C. chinensis exceeded 0.5 . Therefore, the optimal precipitation of $C$. chinensis in the coldest season ranges from $0 \mathrm{~mm}$ to $2000 \mathrm{~mm}$ and the survival probability exceeds 0.5 .

\section{Model application}

Global C. chinensis distribution

The global C. chinensis distribution is shown in Fig. 2. in Asia, C. chinensis are mainly distributed at latitudes ranging from $20^{\circ}$ to $50^{\circ}$, which includes central, eastern, and southern China. C. chinensis also has a small distribution in Japan, India, Afghanistan, Pakistan, Myanmar, Vietnam, Bangladesh, and Turkey as well as minor occurrences in Australia.

Habitat suitability simulation for three historical periods

The simulation results of the $\mathrm{C}$. chinensis habitat suitability during three historical periods (last glacial maximum, mid-Holocene, and 1960-1990) are shown in Fig. 3a-c. From the perspective of space, suitable areas for $\mathrm{C}$. chinensis during these three periods concentrated in the central, northern, southern, and eastern parts of China. These areas have a survival probability above 0.5 , indicating that $\mathrm{C}$. chinensis in these region benefitted from moderate or relatively high suitability. Compared with the last glacial maximum, the 
paleoclimatic prediction of the Holocene mid-term CCSM4 climate model indicates that the position in the mid-Holocene changed; moreover, it indicated that the size of the predicted distribution increased. From the mid-Holocene to 1960-1990, the global habitat suitability of C. chinensis gradually decreased, and the area with medium and relatively higher fitness $(>0.5)$ gradually decreased. From the last glacial maximum to the mid-Holocene, the total area with suitability above 0.75 increased by 0.5689 million $\mathrm{km}^{2}$ (i.e., by $25.09 \%$ ). The area with higher fitness $(>0.75)$ during the mid-Holocene reached 2.8362 million $\mathrm{km}^{2}$, accounting for $1.9 \%$ of the global total area. However, from the mid-Holocene to 1960-1990, the total area with suitability above 0.75 decreased by 0.0797 million $\mathrm{km}^{2}$ (i.e., by $2.81 \%$ ). During the period of $1960-1990$, the area with high fitness (>0.75) was 2.7565 million $\mathrm{km}^{2}$, accounting for $1.85 \%$ of the global total area. From the last glacial maximum to the mid-Holocene, the total area with suitability of $0.5-1$ increased by 0.0875 million $\mathrm{km}^{2}$, while from the mid-Holocene to $1960-1990$, the total area with suitability of 0.5-1 decreased by 0.0759 million $\mathrm{km}^{2}$.

Suitable habitat distributions under global warming scenarios

The computed results for the C. chinensis habitat suitability in RCP2.6 and RCP8.5 are shown in Fig. 4a and Fig. $4 \mathrm{~b}$, respectively. The suitable habitats of $C$. chinensis decreased in response to climatic warming. In RCP8.5, the total areas with intermediate suitability and high suitability for the survival of $C$. chinensis was less than that of RCP2.6 (Fig. 4a). In RCP2.6, the C. chinensis suitabilities of northern, central, and southern China, North Korea, and the coastal areas of Japan all exceed 0.75 . However, the suitabilities of southern Africa, the central and southern parts of North America, and South America ranged between 0.25 and 0.5, while the habitat suitability of the remaining areas was below 0.25 (Fig. 4a). In RCP2.6, the area with suitable habitat was below 0.25 (about 141 million $\mathrm{km}^{2}$ ), accounting for $94.6 \%$ of the global area. Areas where the habitat suitability ranged between 0.25 and 0.5 , as well as between 0.5 and 0.75 accounted for $2.0 \%$ and $1.5 \%$ of the world, respectively, with areas of about 2.9526 million $\mathrm{km}^{2}$ and 2.2519 million $\mathrm{km}^{2}$, respectively. Habitats with suitability exceeding 0.75 accounted for $1.91 \%$ of the total area of the world. In RCP8.5, the area suitable for $\mathrm{C}$. chinensis growth between 0.25 and 0.5 was the same as in RCP2.6, and its distribution concentrated in the central and southern parts of North America and South America (Fig. 4b). Moreover, habitats with suitability above 0.75 were also distributed in Northern China, North Korea, and the coastal areas of Japan. Compared with RCP2.6, for RCP8.5, the areas with high suitability for survival increased by 0.052 million $\mathrm{km}^{2}$; however, areas with intermediate suitability and high suitability for survival decreased by 0.18 million $\mathrm{km}^{2}$. Areas with habitat suitability below $0.25 \%$ accounted for $94.8 \%$ of the world's total area, with an area of 141 million $\mathrm{km}^{2}$. Compared with PCR2.6, this indicates an increase of 0.3298 million $\mathrm{km}^{2}$. Therefore, in general, habitats suitable for $\mathrm{C}$. chinensis decreased in response to climate warming.

\section{Discussion}

\section{Relationship between $\mathrm{C}$. chinensis habitat suitability and environmental variables}


Temperature and precipitation are two climatic features that can be used as useful starting points to investigate the mechanisms with which the global climate controls plant distribution [53]. Among the six bioclimatic variables adopted for the developed model, annual mean temperature (Bio1), isothermality (Bio3), precipitation seasonality (Bio15), and precipitation of the warmest quarter (Bio18) were the most important contributors to the habitat suitability of $\mathrm{C}$. chinensis as indicated by their high weights when used independently. The suitable annual average temperature of $\mathrm{C}$. chinensis was identified to range within 11$37^{\circ} \mathrm{C}$. This suitable temperature fits the suitable germination temperature of $\mathrm{C}$. chinensis. $\mathrm{C}$. chinensis begins to germinate (the germination rate of $\mathrm{C}$. chinensis is $7.3 \%$ ) at a temperature of $10^{\circ} \mathrm{C}$, and the germination rate increases with increasing temperature [54]. When the temperature reaches $25-35^{\circ} \mathrm{C}$, the germination rate of $\mathrm{C}$. chinensis reaches $40-46 \%$ [54]. When the temperature reaches $40{ }^{\circ} \mathrm{C}$ or above, the germination rate of $\mathrm{C}$. chinensis is 0 [54]. The isothermality is the mean diurnal range vs. the temperature annual range, which has been shown to affect the distribution of tree species [55]. The distribution of $\mathrm{C}$. chinensis is also affected by isothermality. When Bio3 ranged from 0 to 45 , the survival probability of $\mathrm{C}$. chinensis exceeded 0.5. Precipitation changes during the growing season affect the growth of plants and their primary productivity [56]. In this study, the suitable precipitation of the warmest quarter was $300-1000 \mathrm{~mm}$ and $2500-3500 \mathrm{~mm}$ for $C$. chinensis growth, indicating that $C$. chinensis prefers a warm and humid environment [57]. C. chinensis has a disjunct distribution in Australia and Asia, which is likely the result of its relatively recent long-distance dispersal [28]. The main distribution areas of C. chinensis in China include the provinces of Henan, Jiangsu, Shandong, Hebei, Jilin, and Liaoning [34]. Recently, new records of C. chinensis have been reported for Bhubaneswar, Odisha, India, and Sikkim $[58,59]$. The current distribution of $\mathrm{C}$. chinensis might be the result of vegetation changes due to climatic changes, which include temperature and precipitation.

\section{Habitat suitability simulation for three historical periods}

The results of this prediction indicated that from the last glacial maximum to the mid-Holocene, the global habitat suitability of $\mathrm{C}$. chinensis gradually increased. Compared with its current distribution, $\mathrm{C}$. chinensis benefitted from a larger area with suitable climate during the mid-Holocene period. Research has shown that the warming and increased precipitation at around $6000 \mathrm{BP}$ greatly affected the European vegetation [60]. As shown in Fig. 3, in Western Europe, the survival probability during the mid-Holocene increased significantly compared with the last glacial maximum. This might be the result of the increased temperature and precipitation during the mid-Holocene, which results in an increase of the suitable survival area of $\mathrm{C}$. chinensis $[61,62]$. In addition, $\mathrm{C}$. chinensis might grow better under the prevailing higher $\mathrm{CO}_{2}$ conditions during the mid-Holocene $[61,62]$. However, from the mid-Holocene to 1960-1990, the global habitat suitability of $\mathrm{C}$. chinensis gradually decreased. The possible reason might be habitat loss, which affects the distribution of species [63]. Meulebrouck et al. reported a significant decline of many wasteland species in Western Europe over the recent decades due to habitat loss [63].

Moreover, C. chinensis is a holoparasitic plant, which absorbs both water and nutrients from host plants by haustaria and fully relies on their host [64]. Using Maxent modeling, this study found that the trends of the global habitat suitability of the host (Glycine max) of C. chinensis during these three historical periods were 
the same as that mentioned above (Ren et al., unpublished data). This indicates that the habitat suitability of the host would also affect the habitat suitability of the parasite.

\section{Changes in distribution of $\mathrm{C}$. chinensis in the future}

From the perspective of the overall ecological suitability of C. chinensis, in RCP8.5, the area suitable for the survival of $\mathrm{C}$. chinensis was less than that of RCP2.6. Global warming thus seems to have limited the growth of $\mathrm{C}$. chinensis and negatively impacted the global habitat suitability and suitable areas for $\mathrm{C}$. chinensis. This may be because transitory or constantly high temperatures cause an array of morpho-anatomical, physiological, and biochemical changes in plants. These affect plant growth and development [65], and decrease the productivity of both above-ground plant parts and roots [66].

As mentioned above, the suitability of the host can also affect the future suitability of parasites. Using Maxent modeling, this study found that the suitability area of the host G. max in RCP8.5 was less than in RCP2.6 (Ren et al., unpublished data), indicating that global warming also negatively affects the suitable area of the host and consequently reduced the suitable area of parasites by limiting plant growth. In previous literature, several researchers reported that the yield of rice (Oryza sativa), chillies (Capsicum annuum), and tomato (Solanum lycopersicon), other hosts of C. chinensis [67], significantly decreased under global warming $[68,69,70]$. This might also reduce the suitability of both hosts and parasites.

As shown in Fig. 4, in the future, C. chinensis has a probability of habitat suitability ranging within $0.25-0.5$ in both South America and North America under global warming, although C. chinensis is currently not distributed there. This might be due to two reasons. First, the temperature and precipitation in South America and North America increased in response to global warming. For example, Ramos da Silva and Haas [71] reported that the overall temperature of South America increased, and precipitation also increased in southern Brazil and the western Amazon in response to global warming. Karmalkar and Bradley [72] showed that the temperature in North America will have increased appropriately by 2050. Projections of the winter precipitation for the eastern USA (including the Northeast) and the Midwest (mostly CMIP5 models) indicate a wetter future. Secondly, with increasing temperature and precipitation, the stronger growth of the $\mathrm{C}$. chinensis's host Triticum aestivum [73], a main host of crop in both North and South America [74], might drive the invasion of $\mathrm{C}$. chinensis from its suitability area to North America and South America.

\section{Conclusion}

The existence and potentially suitable habitat of $\mathrm{C}$. chinensis were assessed and predicted by using the best Maxent modeling evaluated by both the AUC index and TSS index. Six important bioclimatic variables that influence species distribution were selected from a total of 19 bioclimatic variables. These are annual mean temperature, isothermality, temperature seasonality, precipitation seasonality, precipitation of the warmest quarter, and precipitation of the coldest quarter. Controlling temperature and precipitation can both prevent and protect $\mathrm{C}$. chinensis. The suitable habitat of $\mathrm{C}$. chinensis is mainly distributed in China. Compared with its current distribution, the mid-Holocene period offered a larger climatically suitable area for $\mathrm{C}$. chinensis, and central and southern China were particularly suitable. The simulation results of $\mathrm{C}$. chinensis habitat 
suitability in RCP2.6 and RCP8.5 indicated that the C. chinensis habitat suitability decreased due to the warming climate. This indicates a decreasing trend for the $\mathrm{C}$. chinensis distribution in the future. In addition to the above bioclimatic variables, other factors may also affect the suitable habitat of plants, such as soil, geographic barriers, human disturbance, and host distribution $[65,66]$. Although this study only considered the impact of the climate on $\mathrm{C}$. chinensis, if the effects of human activities, geographic barriers, soil conditions on vegetation, and host distribution were to be comprehensively considered, the distribution of $\mathrm{C}$. chinensis could be more accurately predicted. However, a flaw affects the accuracy of ENMs, which critically hinges on the quality of the occurrence data and often uses haphazardly collected data. Although the maximum number of background points was set to 10000 , to match the bias of the buffer of appearance records, the utilized background records were constrained to Asia.

\section{Declarations}

\section{Ethics approval and consent to participate}

Not applicable.

\section{Consent for publication}

Not applicable.

\section{Availability of data and material}

All raw data will be deposited in Dryad after accept.

\section{Competing interests}

The authors declare that they have no competing interests.

\section{Funding}

The study was financially supported by the Inter-governmental S\&T Cooperation Proposal between Bulgaria and China (No.15-2) and the National Science Fund of the Bulgarian Ministry of Education and Science, grant DNTS China 01/5.

\section{Authors' contributions}

$\mathrm{JL}, \mathrm{LZ}$, and MY conceived the ideas, designed methodology and led the writing of the manuscript. JM collected the data. ZR analysed the data and write the draft manuscript. All authors contributed critically to the drafts and gave final approval for publication.

\section{Acknowledgements}

We thank Jizhong Wan for the data collection.

\section{References}


1. Fang JY. Ecoclimatological analysis of the forest zones in China. Acta Ecologica Sinica. 1990;11:377387.

2. Yi YJ, Cheng $X$, Yang ZF, Zhang SH. Maxent modeling for predicting the potential distribution of endangered medicinal plant ( riparia Lour) in Yunnan, China. Ecological Engineering. 2016;92:260-269.

3. Qin A, Liu B, Guo Q, Bussmann RW, Ma F, Jian Z, Xu G, Pei S. Maxent modeling for predicting impacts of climate change on the potential distribution of Thuja sutchuenensis, an extremely endangered conifer from southwestern China. Global Ecology and Conservation. 2017;10:139-146.

4. Ma B, Sun J. Predicting the distribution of Stipa purpurea across the Tibetan Plateau via the MaxEnt model. BMC Ecology. 2018;18:10.

5. Xu YJ, Chen YN, Li WH, Fu AH, Ma XD, Gui DW, Chen YP. Distribution pattern of plant species diversity in the mountainous Region of Ili River Valley, Xinjiang. Environmental Monitoring and Assessment. 2011;177(1-4):681-694.

6. Schnitzler J, Linder HP, Graham CH, Dormann CF, Katja S. Climatic niche evolution and species diversification in the Cape flora, South Africa. Journal of Biogeography. 2012; 39:2201-2211.

7. Shirk AJ, Cushman SA, Waring KM, Wehenkel CA, Leal-Sáenz A, Toney C, Lopez-Sanchez CA. Southwestern white pine ( Pinus strobiformis) species distribution models project a large range shift and contraction due to regional climatic changes. Forest Ecology and Management. 2018;411:176-186.

8. Pandey PC, Anand A, Srivastava PK. Spatial distribution of mangrove forest species and biomass assessment using field inventory and earth observation hyperspectral data. Biodiversity and Conservation. 2019.

9. Barbet-Massin M, Rome Q, Villemant C, Courchamp F. Can species distribution models really predict the expansion of invasive species? PLoS One. 2018;13:e193085.

10. Motloung RF, Robertson MP, Rouget M, Wilson JRU. Forestry trial data can be used to evaluate climatebased species distribution models in predicting tree invasions. Neobiota. 2018;20:31-48.

11. Wang D, Cui BC, Duan SS, Chen JJ, Fan H, Lu BB, Zheng JH. Moving north in China: The habitat of Pedicularis kansuensis in the context of climate change. Science of The Total Environment. 2019;697. dio: 10.1016/j.scitotenv.2019.133979.

12. Zhang C, Chen L, Tian CM, Li T, Wang R, Yang QQ. Predicting the distribution of dwarf mistletoe (Arceuthobium sichuanense) with GARP and Maxent models.Journal of Beijing Forestry University. 2016;38(5):23-32. dio:10.13332/j.1000-1522.20150516

13. Hershey DR. Myco-heterophytes\& parasitic plants in food chains. The American Biology Teacher. 1999;61:575-578.

14. Pennings SC, Callaway RM. Parasitic plants: parallels and contrasts with herbivores. Oecologia. 2002;131:479-489.

15. Commission CP. Pharmacopoeia of the People's Republic of China. Beijing: Chemical Industry Press. 2000 .

16. Wang T, Zhang X, Xie W. Cistanche deserticola Y. C. Ma, "Desert Ginseng": A Review. The American Journal of Chinese Medicine. 2012;40(6):1123-1141. 
17. Chen BN, Yang GE, Li JK, Du HJ, Shan Q, Zhang ZM. Cytotoxic constituents from Viscum coloratum. Chemistry of Natural Compounds. 2009;45(4):547-549.

18. Sillero, N. What is the eco-modeling model? A proposed classification of organic healthy niche models based on their underlying methods. Ecological Modeling. 2011;222: 1343-1346.

19. Warren DL, Seifert SN. Ecological niche modeling in Maxent: the importance of model complexity and the performance of model selection criteria. Ecological Applications. 2011;21:335-342.

20. Elith J, Leathwick JR. Species distribution models: ecological explanation and prediction across space and time. Annual Review of Ecology, Evolution, and Systematics. 2009;40:677- doi:

10.1146/annurev.ecolsys.110308.120159.

21. Fitzpatrick MC, Gotelli NJ, Ellison AM. MaxEnt versus MaxLike: empirical comparisons with ant species distributions. Ecosphere. 2013;4(5):1- doi: 10.1890/ES13-00066.1.

22. Merow C, Smith MJ, Silander JA. A practical guide to MaxEnt for modeling species' distributions: what it does, and why inputs and settings matter. Ecography. 2013;36(10):1058- doi: 10.1111/j.16000587.2013.07872.x.

23. Phillips SJ, Anderson RP, Schapire RE. Maximum entropy modeling of species geographic distributions. Ecological Modelling. 2006;190:231-259.

24. Elith J, Graham CH, Anderson RP, Dudik M, Ferrier S, Guisan A, Hijmans RJ, Huettmann F, Leathwick JR, Lehmann A. Novel methods improve prediction of species' distributions from occurrence data. Ecography. 2006;29:129-151.

25. Rebelo H, Jones G. Ground validation of presence-only modelling with rare species: a case study on barbastelles Barbastella barbastellus (Chiroptera: Vespertilionidae). Journal of Applied Ecology. 2010;47:410-420.

26. Elith J, Phillips SJ, Hastie T, Dudík M, Chee YE, Yates CJ. A statistical explanation of maxent for ecologists. Diversity and Distributions. 2011;17:43-57.

27. Marcer A, Sáez L, Molowny-Horas R, Pons X, Pino J. Using species distribution modelling to disentangle realised versus potential distributions for rare species conservation. Biological Conservation. 2013;166:221-230.

28. Costea M, Spence I, Stefanović S. Systematics of Cuscuta chinensis species complex (subgenus Grammica, Convolvulaceae): evidence for long-distance dispersal and one new species. Organisms Diversity \& Evolution. 2011;11:373-386.

29. Mavlonov GT, Ubaidullaeva KA, Kadryaeva GV, Kuznetsova NN. Cytotoxic components of Cuscuta. Chemistry of Natural Compounds. 2008;44:409-410.

30. Wu ZY. Flora of China. Science Press, Beijing. 2006.

31. Rahmatullah M, Sultan S, Toma TT, Lucky SA, Chowdhury MH, Haque WM, Annay EA, Jahan R. Effect of Cuscuta reflexa stem and Calotropis procera leaf extracts on glucose tolerance in glucose-induced hyperglycemic rats and mice. African Journal of Traditional, Complementary and Alternative Medicines Ajtcam. 2009;7:109-112.

32. Donnapee S, Jin L, Xi Y, Ge AH, Donkor PO, Gao XM, Chang YX. Cuscuta chinensis : A systematic review on ethnopharmacology, phytochemistry and pharmacology of an important traditional herbal medicine. 
Journal of Ethnopharmacology. 2014;157:292-308.

33. Beck J, Ballesteros-Mejia L, Nagel P, Kitching I. Online solutions and the 'Wallacean shortfall': What does GBIF contribute to our knowledge of species' ranges? Diversity and Distributions. 2013;19(7):1043-1050.

34. Moss R, Babiker M, Brinkman S, Calvo E, Carter T, Edmonds J, Elgizouli I, Emori S, Erda L, Hibbard K, Jones R, Kelleher MK, Lamarque JF, Manning M, Matthews B, Meehl J, Meyer L, Mitchell J, Nakicenovic N, Neill BO, Pichs R, Riahi K, Rose S, Runci P, Stouffer R, Van Vuuren D, Weyant J, Wilbanks T, Pascal J, Van YperseleZurek M. Towards New Scenarios for Analysis of Emissions, Climate Change, Impacts, and Response Strategies. Geneva: Intergovernmental Panel on Climate Change. 2008.

35. John W, Christian A, Mikiko K, Jiang K, Nakicenovic N, Shukla PR, La RE, Gary Y. Report of 2.6 Versus 2.9 Watts/m² RCPP Evaluation Panel. Geneva, Switzerland: IPCC Secretariat. 2009.

36. Nolan C, Overpeck JT, Allen JRM, Anderson P, Betancourt J, Binney HA, Brewer S, Bush MB, Chase BM, Cheddadi R, Djamali M, Dodson JR, Edwards ME, Gosling WD, Haberle S, Hotchkiss SC, Huntley B, Ivory S, Kershaw P, Kim S-H, Latorre C, Michelle L, Lezine A-M, Liu K-b, Liu Y, Anatoly L, Mcglone M, Marchant RA, Momohara A, Moreno PI, Müller SL, Otto-Bliesner B, Shen C, Stevenson J, Takahara H, Tarasov PE, Tipton J, Vincens A, Weng CY, Xu QH, Zheng Z, Jackson ST. Past and future global transformation of terrestrial ecosystems under climate change. Science. 2018;361: 920.

37. Van Vuuren DP, Edmonds J, Kainuma M, Riahi K, Thomson A, Hibbard K, Hurtt GC, Kram T, Krey V, Lamarque JF, Masui T, Meinshausen M, Nakicenovic N, Smith SJ, Rose SK. The representative concentration pathways: an overview. Climatic Change. 2011;109(1):5-31. dio:10.1007/s10584-0110148-z.

38. Du JJ, Chen ZW. Method of path analysis with SPSS linear regression. Bulletin of Biology. 2010;45:4-6.

39. Sun Y, Shi MC, Peng H, Zhu PL, Liu SL, Wu SL, He C, Chen F. Forest lighting fire forecasting for Daxing'anling Mountains based on Maxent model. Chinese Journal of Applied Ecology. 2014;25:11001106.

40. Phillips SJ, Dudík M. Modeling of species distributions with Maxent: new extensions and a comprehensive evaluation. Ecography. 2008;31:161-175.

41. Liu ZS, Gao H, Teng LW, Su Y, Wang XQ, Kong FY. Habitat suitability assessment of blue sheep in Helan Mountain based on MAXENT modeling. Acta Ecologica Sinica. 2013; 33:7243-7249.

42. Merow C, Jr JAS. A comparison of Maxlike and Maxent for modeling species distributions. Methods in Ecology and Evolution. 2014;5:215-225.

43. Hu ZJ, Zhang YL, Yu HB. Simulation of Stipa purpurea distribution pattern on Tibetan Plateau based on MaxEnt model and GIS. Chinese Journal of Applied Ecology. 2015;26:505-511.

44. Phillips SJ, Dudík M, Schapire RE. A Maximum Entropy Approach to Species Distribution Modeling. International Conference on Machine Learning. 2004.

45. Phillips SJ, Anderson RP, Dudík M, Schapire RE, Blair ME. Opening the black box: an open-source release of Maxent. Ecography. 2017;40.

46. Allouche O, Tsoar A, Kadmon R. Assessing the accuracy of species distribution models: prevalence, kappa and the true skill statistic (TSS). Journal of Applied Ecology. 2006;43:1223-1232.

47. Swets JA. Measuring the accuracy of diagnostic systems. Science. 1988;240:1285-1293. 
48. Vanagas G. Receiver operating characteristic curves and comparison of cardiac surgery risk stratification systems. Interact Cardiovasc Thorac Surg. 2004;3: 319-322.

49. Morales NS, Fernández IC, Baca-González C. MaxEnt's parameter configuration and small samples: are we paying attention to recommendations? A systematic review. PeerJ. 2017;5:e3093. doi: 10.7717/peerj.3093.

50. Li GQ, Sheng D, Guo K. Evaluation of Limiting Climatic Factors and Simulation of a Climatically Suitable Habitat for Chinese Sea Buckthorn. PLoS One. 2015;10(7):e0131659. doi:

10.1371/journal.pone.0131659.

51. Barros, FSM, De Siqueira MF, Da Costa DP. Modeling the potential geographic distribution of five species of Metzgeria Raddi in Brazil, aiming at their conservation. The Bryologist. 2012;115(2):341-349.

52. Lei JC, Xu HG. MaxEnt-based prediction of potential distribution of Solidago canadensis in China. Journal of Ecology and Rural Environment. 2010;26(2): 137-141.

53. Woodward FI, Williams BG. Climate and plant distribution at global and local scales. 1987, 69: 189-197.

54. Wang GY, Wen JF, Chen GH, Dong ZF, Dong ZT, Ye DN. Biological characteristics observation and control measures of Cuscuta Chinensis. Plant Quarantine. 2007;21(6):351-352.

55. Amissah L, Mohren GMJ, Bongers F, Hawthorne WD, Poorter L. Rainfall and temperature affect tree species distribution in Ghana. Journal of Tropical Ecology. 2014;30(05):435-446.

56. Zhang H, Wang XP, Zhang YF, Hu R, Pan YX, Chen N. Responses of plant growth of different life forms to rainfall amount changes in an arid desert area. Chinese Journal of Ecology. 2015;34:1847-

57. Men XY, Bai SZ. Northern medicinal dodder cultivation technology. Seed World. 2004;41.

58. Kalidass C. Cuscuta chinensis (Convolvulaceae) - A new record for Odisha. Journal of Economic and Taxonomic Botany. 2015;39:124-125.

59. O'Neill AR, Chhetri PK, Chhetri B. First record of Cuscuta chinensis (Convolvulaceae) in the Sikkim eastern Himalaya. International Journal of Botany and Research (IJBR). 2016;6: 2319-4456.

60. Garzón MB, Sánchez de Dios R, Ollero HS. Predictive modelling of tree species distributions on the Iberian Peninsula during the Last Glacial Maximum and Mid-Holocene. Ecography. 2007;30(1):120-134.

61. Childe VG. Man Makes Himself. New American Library, New York, USA. 1951.

62. Sage RF. Was Low Atmospheric $\mathrm{CO}_{2}$ during the Pleistocene a Limiting Factor for the Origin of Agriculture. Global Change Biology. 1995;1: 93-

63. Meulebrouck K, Ameloot E, Verheyen K, Hermy M. Local and regional factors affecting the distribution of the endangered holoparasite Cuscuta pithymumin heathlands. Biological Conservation. 2007;140:8-18.

64. Wahida A, Gelania S, Ashraf M, Foolad MR. Heat tolerance in plants: An overview. Environmental and Experimental Botany. 2007;61(3):199-223.

65. Pearson RG, Dawson TP. Long-distance plant dispersal and habitat fragmentation: identifying conservation targets for spatial landscape planning under climate change. Biological Conservation. 2005;123:389-401.

66. Kunstler G, Lepart J. Fagussy/vatica recruitment across a fragmented Mediterranean landscape, importance of long distance effective dispersal, abiotic conditions and biotic interactions. Diversity 
Distrib. 2007;13:799-807.

67. Marambe B, Wijesundara DSA, Tennakoon KU, Pindeniya D. Growth and development of Cuscuta chinensis and its impact on selected crops. Weed Biology and Management. 2002;2(2):79-83.

68. De Boecka HJ, Lemmens CMHM, Gielen B, Bossuyt H, Malchair S, Carnol M, Merckx R, Ceulemans R, Nijs I. Combined effects of climate warming and plant diversity loss on above- and below-ground grassland productivity. Environmental and Experimental Botany. 2007;60(1):95-104.

69. Bhutia KL, Khanna VK, Meetei TNG, Bhutia ND. Effects of Climate Change on Growth and Development of Chilli. Agrotechnology. 2018;7:2. doi: 10.4172/2168-9881.1000180.

70. Biratu W. Review on the Effect of Climate Change on Tomato (Solanum Lycopersicon) Production in Africa and Mitigation Strategies. Journal of Natural Sciences Research. 2018;Vol.8, No.5.

71. Ramos da Silva R, Haas R. Ocean Global Warming Impacts on the South America Climate. Earth Science. 2016. doi: 10.3389/feart.2016.00030.

72. Karmalkar AV, Bradley RS. Consequences of Global Warming of $1.5^{\circ} \mathrm{C}$ and $2{ }^{\circ} \mathrm{C}$ for Regional Temperature and Precipitation Changes in the Contiguous United States. Plos One. 2017. doi: 10.1371/journal.pone.0168697.

73. Moorthy BTS, Mishra JS, Bhan M, Dubey RP. Effect of Different Densities of Cuscuta chinensis on Lentil and Chickpea. National Research Centre for Weed Science. 2004;36(3®4):221-223.

74. Garcia-Alonso M, Hendley P, Bigler F, Mclean MA. Transportability of confined field trial data for environmental risk assessment of genetically engineered plants: a conceptual framework. Transgenic Research. 2014;23(6):1025-41. doi: 10.1007/s11248-014-9785-0.

\section{Supplementary Information}

Fig.S1. The results of the jackknife test of variable contribution in modeling the habitat distribution of Cuscuta chinensis. The regularized training gain describes how much better the Maxent distribution fits the data compared to a uniform distribution. The dark blue bars indicate the gains from using each variable in isolation, while the light blue bars indicate the gains lost by removing a single variable from the full model. The red bar indicates the gains when all variables are used.

Fig.S2. Response curves of eight main bioclimatic variables. The red curve showed the mean response calculated over 10 replicates, while the blue margin showed the standard deviation calculated over 10 replicates. The temperature data are expressed in ${ }^{\circ} \mathrm{C} * 10$. This means that the value of 231 represents 23.1 ${ }^{\circ} \mathrm{C}$. The unit used for precipitation data is $\mathrm{mm}$ (Bio1: annual mean temperature $\left({ }^{\circ} \mathrm{C}\right)$; Bio3: isothermality (BIO2 / BI07) (* 100); Bio4: temperature seasonality (standard deviation *100); Bio15: precipitation seasonality (coefficient of variation); Bio18: precipitation of warmest quarter (mm); Bio19: precipitation of coldest quarter $(\mathrm{mm}))$.

\section{Figures}




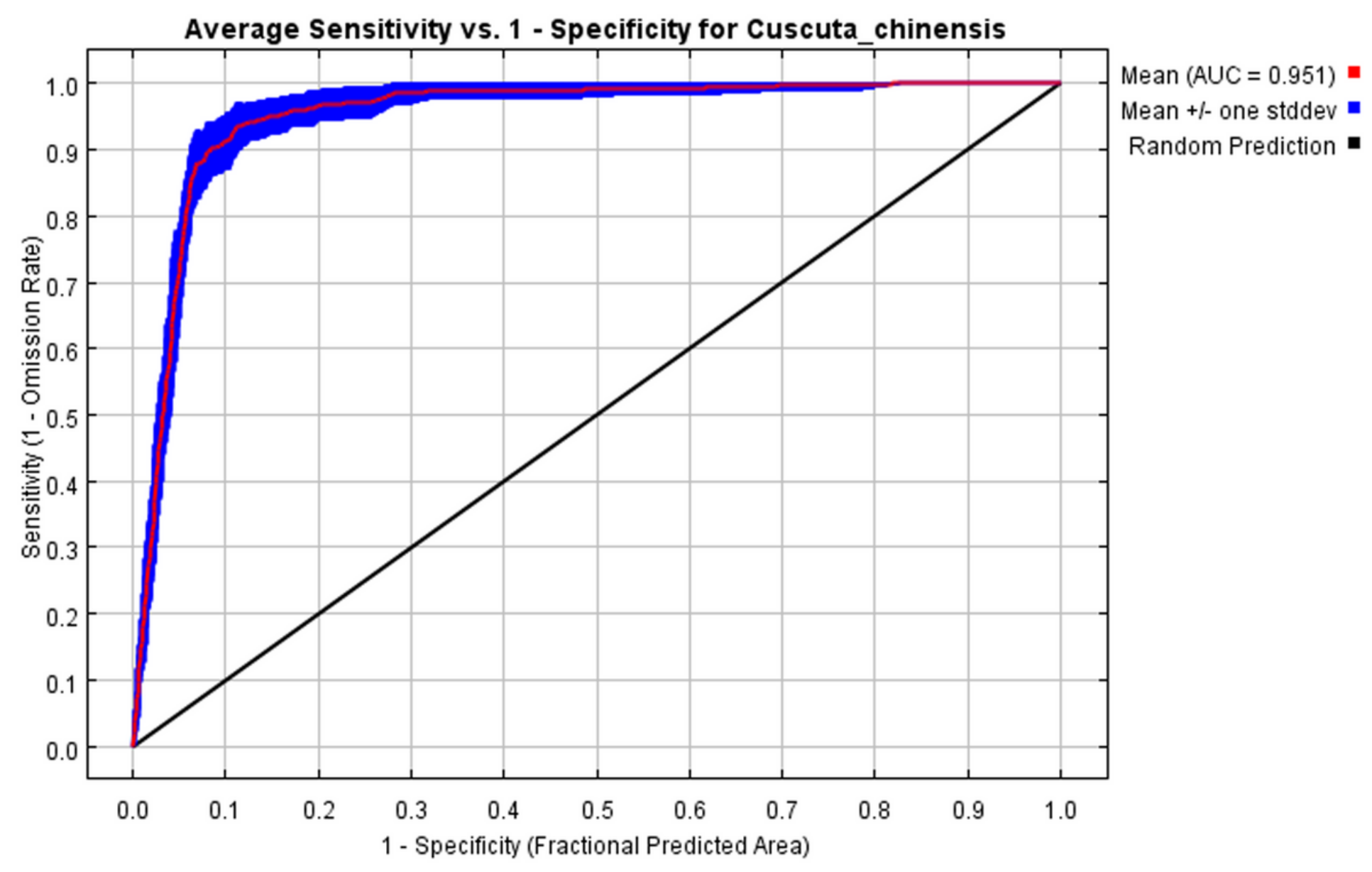

Figure 1

Results of the area under curve in developing Cuscuta chinensis habitat suitability model. The red line (training) indicates the fit of the model to the training data. The blue line (testing) indicates the fit of the model to the testing data and is the real test of the model's predictive power.

\section{Figure 2}

Global distribution of Cuscuta chinensis. Note: The designations employed and the presentation of the material on this map do not imply the expression of any opinion whatsoever on the part of Research Square concerning the legal status of any country, territory, city or area or of its authorities, or concerning the delimitation of its frontiers or boundaries. This map has been provided by the authors.

\section{Figure 3}

Habitat suitability distribution of Cuscuta chinensis for three historical periods.(a) Last glacial maximum, (b) mid-Holocene, and (c) 1960-1990. Note: The designations employed and the presentation of the material on this map do not imply the expression of any opinion whatsoever on the part of Research Square concerning 
the legal status of any country, territory, city or area or of its authorities, or concerning the delimitation of its frontiers or boundaries. This map has been provided by the authors.

\section{Figure 4}

Suitable habitat distribution of Cuscuta chinensis for two global warming scenarios. (a) RCP2.6, (b) RCP8.5. Note: The designations employed and the presentation of the material on this map do not imply the expression of any opinion whatsoever on the part of Research Square concerning the legal status of any country, territory, city or area or of its authorities, or concerning the delimitation of its frontiers or boundaries. This map has been provided by the authors.

\section{Supplementary Files}

This is a list of supplementary files associated with this preprint. Click to download.

- Fig.S2.tif

- Fig.S1.tif 